\title{
Food habits in overweight and obese adolescent girls with Polycystic ovary syndrome (PCOS): a qualitative study in Iran
}

\author{
Leila Hajivandi ${ }^{1,2}$, Mahnaz Noroozi $^{3^{*}}$ D, Firoozeh Mostafavi ${ }^{4}$ and Maryam Ekramzadeh ${ }^{5}$
}

\begin{abstract}
Background: Polycystic ovary syndrome (PCOS) is a hormonal disorder in women of reproductive age. It seems that over the recent years, PCOS has augmented in adolescent girls due to unhealthy food habits and obesity. So, the present study was conducted to explore the food habits in overweight and obese adolescent girls with PCOS.

Methods: In the present qualitative study, 33 participants were selected using a purposive sampling method. Data were collected through individual in-depth interviews, focus group discussions (FGDs), and field notes. These data were analyzed through the use of conventional qualitative content analysis.

Results: Three main categories were extracted: First, the high consumption of unhealthy food had three subcategories: "high consumption of fatty and salty foods", "high consumption of unhealthy snacks", and "high consumption of sugar-rich foods". Second, low consumption of healthy food had three sub-categories: "low consumption of dairy products", "low consumption of fiber-rich foods", and "low consumption of meat, beans, fish and seafood" Third, inappropriate behavioral habits had three sub-categories: "lack of concentration and consumption of large meals", "inappropriate dietary and physical activity patterns", and "skipping the meals and going on arbitrary diets".

Conclusion: This research through presenting an image of food habits in overweight and obese adolescent girls with PCOS is able to help for designing the necessary interventions to change the food habits, control the symptoms and complications of PCOS, and finally, improve the reproductive health of these girls.
\end{abstract}

Keywords: Polycystic ovary syndrome, Food habits, Adolescent, Qualitative research

\section{Background}

Polycystic ovary syndrome (PCOS) is a hormonal disorder in women of reproductive age [1]. Based on the diagnostic criteria, the prevalence of PCOS among adolescent girls (11-19 years old) is $1.8-15 \%$ [2]. In women and adolescent girls with PCOS, obesity is a pathophysiologic

\footnotetext{
* Correspondence: noroozi@nm.mui.ac.ir

${ }^{3}$ Department of Midwifery and Reproductive Health, School of Nursing and Midwifery, Isfahan University of Medical Sciences, Isfahan, Iran

Full list of author information is available at the end of the article
}

principle, hence the fact that obesity leads to an increase in insulin secretion, resulting in the production of ovarian androgens. Accordingly, a permanent imbalance occurs in sex hormones, causing a disorder in the ovulation process which ultimately entails infertility $[3,4]$.

Obesity is one of the main problems of industrial life. The increasing rates of obesity are largely attributed to lifestyles; including unhealthy dietary habits, like consuming the widely distributed junk, fast food coupled with increasing sedentary lifestyles [5]. Inappropriate

(c) The Author(s). 2020 Open Access This article is licensed under a Creative Commons Attribution 4.0 International License, which permits use, sharing, adaptation, distribution and reproduction in any medium or format, as long as you give appropriate credit to the original author(s) and the source, provide a link to the Creative Commons licence, and indicate if changes were made. The images or other third party material in this article are included in the article's Creative Commons licence, unless indicated otherwise in a credit line to the material. If material is not included in the article's Creative Commons licence and your intended use is not permitted by statutory regulation or exceeds the permitted use, you will need to obtain permission directly from the copyright holder. To view a copy of this licence, visit http://creativecommons.org/licenses/by/4.0/. The Creative Commons Public Domain Dedication waiver (http://creativecommons.org/publicdomain/zero/1.0/) applies to the data made available in this article, unless otherwise stated in a credit line to the data. 
food patterns and behaviors, which result in obesity, are formed in adolescence and continue into adulthood [6, 7]. It seems that over the recent years, PCOS has augmented in adolescent girls due to unhealthy food habits and obesity $[8,9]$. Overweight and obesity are common among many groups of young women with PCOS and may precipitate subsequent reproductive and metabolic disorders that require expensive and invasive care. Attention to nutrition and diet is important in management of these young women [10]. Eleftheriadou et al. indicated adolescent girls with PCOS more likely to eat an evening meal and eat this over an hour later when compared to controls. This study showed that PCOS adolescent girls in general have worse dietary habits than controls [11]. Since overweight and obesity play important roles in the occurrence, progress, and PCOS-induced complications, having ideal weight and healthy nutritional practices can reduce the PCOS-induced complications in adolescent girls. Several studies have introduced weight loss and lifestyle modification as the first step to PCOS treatment [5, 12-15]. Considering the different aspects of lifestyle in adolescent girls with PCOS, determining the food habits of these girls could provide an appropriate context for systematic, comprehensive, cultural-based interventions and caring programs in the society. Because qualitative research is an approach to discovering and describing the experiences of participants and conceptualizing them, it could increase insight and awareness about human experiences. This approach is usually used when there is a need for explaining concepts and their relationships [16]. Thus, the present study was conducted to explore the food habits in overweight and obese adolescent girls with PCOS.

\section{Methods}

This research was conducted using a qualitative approach.

\section{Settings, sampling, and recruitment}

In the present study, adolescent girls with PCOS residing in Shiraz, Iran were selected through purposive sampling. The sampling continued considering the maximum variety in age, educational level, occupation, marital status, body mass index, and duration of the disease. Inclusion criteria were being adolescent girls with PCOS diagnosed by a gynecologist through diagnostic criteria [17], aged 15 to 21 (for diagnosis of PCOS must be at least 2 years past the menarche [17]), willingness to participate in the study, informed consent of the adolescents and their parents (in cases of ages below 18 years), adolescent girls with PCOS being overweight or obese, no history of major psychiatric disorders under medical treatment, no history of chronic diseases such as cardiovascular diseases, diabetes, kidney diseases, etc. prescribed with specific diets. An exclusion criterion was unwillingness to continue collaborating and participating in the study. In the present study, regarding relationships and interactions between adolescent girls with PCOS and healthcare providers (midwives, gynecologists, nutritionists, and endocrinologists) they were selected as information-rich participants through purposive sampling. In this regard, healthcare providers with different working experience recruited for the study. Participants were recruited directly or telephone numbers were obtained and they were subsequently telephoned. Accesses to adolescent girls with PCOS were granted through gynecology clinics and gynecologists' offices. Healthcare providers were accessed through midwives, gynecologists, nutritionists and forensic medicine specialists' offices.

\section{Data collection}

Data were collected through individual in-depth interviews, focus group discussions (FGDs), and taking field notes between November 2016 and October 2017. After reaching eligible participants, none of them refused to participate in the study. The first author (LH) conducted the interviews and FGDs. Other authors have previous interviewing experience and qualitative paper/report writing. Prior to data collection, the first author wrote down initial preconceptions about the study topic based on her previous working experience and from literature review. The interviews with adolescent girls with PCOS started with a general question, "What do you eat during a day? Please explain", after which, the open and interpretative responses of participant guided the process. The interviews with healthcare providers started with a general question, "Based on your experiences what are the food habits of adolescent girls with PCOS? Please explain", after which, the open and interpretative responses of participant guided the process. Individual interviews (lasted 30 to $85 \mathrm{~min}$ ) were performed in places and time desired by the participants. In the present study, amongst adolescent girls with PCOS and healthcare providers, those who were more willing to participate in group discussion than individual interviews participated in group discussions. FGDs were conducted in an agreed place such as gynecology clinics. At the group discussion sessions, the researcher was acting as the facilitator and guide of the discussions, and another person was present to take notes. In the present study, sampling continued until the researcher felt that there wasn't any new data during the analysis, so that after 21 individual interviews (with 10 adolescent girls with PCOS and 11 healthcare providers) and two focused group discussions (one for eight adolescent girls with PCOS and one for four healthcare providers) data saturation was obtained and sampling was completed. In this study, all of the 
Table 1 Demographic characteristics of overweight and obese adolescent girls with PCOS

\begin{tabular}{lll}
\hline Characteristic & Number \\
\hline Age (years) & $15-21$ & 18 \\
Mean (SD) & $17.66( \pm 2.4)$ & \\
Education status & High school or below & 13 \\
& Student in college & 5 \\
Occupation & Student & 15 \\
& Unemployed & 3 \\
Marital status & Single & 13 \\
& Married & 5 \\
BMI (kg/m ${ }^{2}$ ) & More or equal than 25 & 11 \\
& More or equal than 30 & 7 \\
Duration of the disease (years) & Less than 1 & 4 \\
& More than1 & 14 \\
\hline
\end{tabular}

nonverbal behaviors of the interviewees were considered and field notes were taken in this regard. The demographic characteristics of 33 participants are shown in Tables 1 and 2 .

\section{Data analysis}

Data analysis was conducted using qualitative content analysis [16]. The interviews were transcribed verbatim by the first author (LH). Then, the narratives were frequently reviewed to present a general understanding of them. Afterward, sentences and phrases were coded, and similar codes were merged via an inductive approach. In this respect, codes with similar meanings were categorized in one group and sub-categories were created. With a comparison between sub-categories, groups with similar concepts were put in one category to create a main category.

\section{Rigor and trustworthiness}

The findings were validated via different methods such as in-depth interviews in different times and places and a combination of data collection methods such as FGDs and field noting. In this study, transcripts were returned

Table 2 Demographic characteristics of healthcare providers

\begin{tabular}{lll}
\hline Characteristic & & Number \\
\hline Age (years) & Equal or less than 50 & 11 \\
& More than 50 & 4 \\
Occupation & Midwife & 2 \\
& Gynecologist & 6 \\
& Nutritionist & 5 \\
& Endocrinologist & 2 \\
Work experience (years) & Equal or less than 10 & 3 \\
& More than 10 & 12 \\
\hline
\end{tabular}

to participants for comments or corrections. Also, to approve the accuracy of the collected data, at different sessions, coded interviews were shared with four of the participants and their final opinions were achieved; so that member checking could be obtained. The opinions of two experts were also obtained to assure the consistency of the results. In the present study, to increase transferability of the data, results of the study were given to three individuals (adolescent girls with PCOS) with similar characteristics to the participants who did not participate in the study to judge the similarity of the results to their own experiences.

\section{Ethical considerations}

The research was verified by the Ethics Committee ViceChancellor of Research at Isfahan University of Medical Sciences (Ethic Code: IR.MUI.Rec.1395.8.885). The reasons for the study were explained prior to each individual interview and FGD. Also, the issues of informed consent, confidentiality of information, anonymity, and right of avoidance from participation were practiced.

\section{Results}

Following data analysis, 398 codes, nine sub-categories, and three main categories including "high consumption of unhealthy foods", "low consumption of healthy foods", and "inappropriate behavioral habits" were obtained (Table 3).

\section{High consumption of unhealthy foods}

The participants stated that, compared with traditional foods, adolescents were more interested in eating foods such as pizza, lasagna, fries, fast food, and prepared meals such as sandwiches, sausages, as well as sweets, candy, and ice cream. Leaning towards such kinds of food is due to their favorable taste, color, shape, easy accessibility, and advertisements. Participants further highlighted the role of friends and media in the consumption of these foods. High consumption of unhealthy foods has three sub-categories including "high consumption of fatty and salty foods", "high consumption of unhealthy snacks", and "high consumption of sugar-rich foods".

\section{High consumption of fatty and salty foods}

Most of the adolescent girls with PCOS stated that they eat fast food at least twice a week. Also, they usually prefer fast food for dinner. Participating girls mentioned the effective role of friends and peers in fast food consumption. They considered eating fast food with their friends and peers as enjoyable.

"Eating fast food with my friends is fun. Whenever we go out, we eat fast food." (19-year old girl). 
Table 3 Examples of codes, sub- categories, and main categories

\begin{tabular}{|c|c|c|}
\hline Code & Sub-category & Main category \\
\hline $\begin{array}{l}\text {-Abundant use of sauce } \\
\text {-Abundant use of fast food } \\
\text {-Abundant use of prepared food } \\
\text {-Abundant use of fried food }\end{array}$ & High consumption of fatty and salty foods & $\begin{array}{l}\text { High consumption of unhealthy } \\
\text { foods }\end{array}$ \\
\hline $\begin{array}{l}\text {-Eating sweets and ice-cream after meals } \\
\text {-Eating cookies, chocolate, and sweet desert daily } \\
\text {-Daily consumption of cake as a snack or breakfast } \\
\text { - High consumption of soft drink and industrial fruit } \\
\text { juice }\end{array}$ & High consumption of sugar-rich foods & \\
\hline $\begin{array}{l}\text {-Eating snacks immediately after a meal } \\
\text { - Frequent use of junk food as a snack } \\
\text {-Consuming cheese puffs and chips }\end{array}$ & High consumption of unhealthy snacks & \\
\hline $\begin{array}{l}\text { Non-consumption of milk } \\
\text {-Replacing soft-drink with yogurt }\end{array}$ & Low consumption of dairy products & Low consumption of healthy foods \\
\hline $\begin{array}{l}\text { Low consumption of lamb, calf and cow meat } \\
\text {-Low consumption of peas, beans, and lentils } \\
\text {-Low consumption of fish and shrimp }\end{array}$ & Low consumption of meat, beans, fish and seafood & \\
\hline $\begin{array}{l}\text {-No fruit consumption in spite of their availability } \\
\text {-Unwillingness to consume vegetable } \\
\text {-No vegetable consumption in spite of their availability }\end{array}$ & Low consumption of fiber-rich foods & \\
\hline $\begin{array}{l}\text { - Speaking on the cell phone while eating } \\
\text { - Eating while watching TV } \\
\text { - Playing with the cellphone while eating } \\
\text {-Craving for more food } \\
\text { - Eating quickly }\end{array}$ & $\begin{array}{l}\text { Lack of concentration and consumption of large } \\
\text { meals }\end{array}$ & Inappropriate behavioral habits \\
\hline $\begin{array}{l}\text {-Sleeping right after eating } \\
\text {-Long-lasting sitting } \\
\text {-Limited physical activity }\end{array}$ & Inappropriate dietary and physical activity patterns & \\
\hline $\begin{array}{l}\text {-Eliminating breakfast from the daily food program } \\
\text {-Arbitrarily food limitation } \\
\text {-Eliminating dinner for losing weight }\end{array}$ & Skipping the meals and going on arbitrary diets & \\
\hline
\end{tabular}

\section{High consumption of unhealthy snacks}

Adolescent girls with PCOS stated that after a meal, they eat chips or puffs daily, which is very enjoyable for them. They considered the snacks very delicious. Healthcare providers narrated that advertisement in mass media (such as TV), easy access to these foods (even at school), and low price to be an effective factors in high consumption of snacks by adolescents.

\section{"Adolescents really like junk food. They can eat them every day, because food taste is very important for them. And, due to the high fat and salt content of junk food, they are really tasty." (Endocrinologist).}

\section{High consumption of sugar-rich foods}

Adolescent girls with PCOS expressed a great desire to eat sweets, cakes, biscuits and desserts. They reported eating cakes or biscuits and industrial fruit juice for breakfast. According to most of the participating girls, after a meal, they eat at least one pastry or ice cream daily. All participating girls stated that they consume soft drinks with fast food.
“... After lunch, I usually eat ice-cream. I like eating chocolate and sweets. Whenever I feel hungry, I only think of sweet foods like cookies and cakes." (19-year old girl).

Healthcare providers also stated that adolescent girls with PCOS have a strong desire to eat simple carbohydrates, such as sweets and chocolate, especially at main meals and snacks, and generally tend to consume high amounts of sugary foods.

\section{"Adolescent girls with PCOS have a false appetite and a strong desire to eat sweets." (Endocrinologist).}

\section{Low consumption of healthy foods}

Adolescent girls with PCSO did not have a positive attitude toward consuming foods such as dairy products, meat, fruits, vegetables, legumes, and seafood. They stated that they know their importance in daily diet, but could not eat them due to their bad taste and smell. This main category has three sub-categories including "low 
consumption of dairy products", "low consumption of fiber-rich foods", and "low consumption of meat, beans, fish and seafood".

\section{Low consumption of dairy products}

Adolescent girls with PCSO stated that they have a very low tendency to drink milk and other dairy products due to their unpleasant smell and taste, and the ensuing gastro-intestinal problems which occur sometimes.

"I don't like milk, but I sometimes eat yogurt. I can't drink milk, because I don't like the taste." (20-year old girl).

Healthcare providers also narrated that these girls are not interested in milk and other dairy products.

“... Unfortunately, girls at this age are not interested in dairy products at all!!! They only eat ice cream!!!”(Nutritionists).

\section{Low consumption of fiber-rich foods}

Most of the participating girls indicated that they do not prefer to eat vegetables and fruits due to their bad taste. They mentioned that they only eat fruit and vegetables by family force.

"I only eat fruits and vegetables if my mom forces me!!!" (16-year old girl).

\section{Low consumption of meat, beans, fish and seafood}

Adolescent girls with PCSO stated that they were reluctant to consume beans and meat because of their unpleasant taste. Healthcare providers also narrated that although meat is the main source of iron, and it is very effective in the reproductive health of adolescent girls with PCSO, they are not interested in eating it.

"Unfortunately, in many cases, adolescent girls with PCSO are reluctant to eat meat." (Nutritionists).

Adolescent girls with PCSO stated that they were reluctant to consume fish and seafood. They attributed the very unpleasant taste and smell of fish and seafood to the lack of consumption of these foods.

"I hate fish and seafood as they smell very bad When I see them on the table I can't eat anything. I even can't eat a small piece of fish!!!" (18-year old girl).

\section{Inappropriate behavioral habits}

Participants pointed to high-lighted habits such as sleeping immediately after a meal, lack of physical activity, lack of concentration during eating, lack of attention to the amount of food consumed per meal, and over eating. A number of overweight and obese adolescent girls with PCSO try arbitrary diets or often eliminate dinner to lose weight. The sub-categories of inappropriate behavioral habits are "lack of concentration and consumption of large meals", "inappropriate dietary and physical activity patterns", and "skipping the meals and going on arbitrary diets".

Lack of concentration and consumption of large meals Adolescent girls with PCSO narrated that they play with their cell phones, talk or watch TV while eating. This causes them to ignore the amount of food they eat during the meals.

"I often eat lunch in front of the TV. Because, I don't concentrate on eating, I eat a lot!!!" (17-year old girl).

Inappropriate dietary and physical activity patterns Most adolescent girls with PCSO said that they have inactive lives, and almost all of them narrated that they sleep after eating. Also, healthcare providers stated that most adolescent girls are very inactive and they consider exercising difficult and time-consuming.

"... Unfortunately, most adolescent girls are very inactive, and they are not even willing to walk. In addition, they consider studying as their first priority and consider exercising difficult and timeconsuming." (Midwife).

\section{Skipping the meals and going on arbitrary diets}

Healthcare providers stated that most adolescent girls eliminate their meals (especially breakfast) for reasons that are: they have no tendency to eat in the early hours of the day, they are late and have no time for it and they have stayed up late. They mentioned that in order to lose weight, overweight and obese adolescent girls with PCSO go on arbitrary diets such as eliminating dinner or removing certain ingredients from their diet.

"Of course, the role of the family is very important. Even the lifestyle and sleeping habits are important!!!! Families that sleep till noon, eliminate breakfast." (Gynecologist).

\section{Discussion}

The present study was conducted to explore the food habits in overweight and obese adolescent girls with PCOS. The results showed that adolescent girls with PCOS consume a lot of unhealthy foods such as fast food, soft drink, sweets, and junk food. There are emerging global data that women with PCOS have different baseline dietary energy intakes compared with women 
without PCOS. These alterations in diet may exacerbate clinical symptoms and compound risk of chronic disease in patients [18]. Eleftheriadou et al. found that adolescent girls with PCOS had sugar-rich breakfasts and consume more daily calories than the control group [11]. Zhang et al. also showed that high intake of total energy and fat were found in PCOS women (aged 12-44 years) [19].

The results of the present study showed that adolescent girls with PCOS consume a small amount of healthy foods such as fiber-rich foods, meat, beans, fish, seafood, and dairy products. Eleftheriadou et al. also showed that girls with PCOS were less likely to have cereals for breakfast and as a result consumed less fiber than controls [11]. Hmedeh et al. concluded in their study, a properly managed diet combined with a balanced lifestyle addresses insulin resistance, cardiovascular health and metabolism, all of which target PCOS symptoms and alleviate them [20].

The results of the present study showed that most overweight and obese adolescent girls with PCOS have little physical activity, skip the meals (especially breakfast), eat fast and consume large meals. In this regard, the results of the study by Amirjani et al. showed that in comparison with the control group, lifestyle scores were lower in the PCOS group in the fields of physical activity [21]. Also, Eleftheriadou et al. showed that girls with PCOS engaged in physical activities less than controls. Even when they did, the frequency and intensity of exercise was less [22]. Zhang et al. concluded that women with PCOS (aged 12-44 years) should avoid long-term sedentary lifestyle habits and focus on adding to the duration of, or enhancing the intensity of physical activity [19]. Vatopoulou \& Tziomalos showed that weight loss and lifestyle changes appear to be effective in obese adolescents with PCOS [23]. So, consultation with overweight and obese adolescent girls with PCOS about the importance of nutrition control, as well as appropriate physical activity, is essential. In this regard, Carolo et al. concluded in their study, overweight and obese adolescent girls with PCOS who lost weight changed their dietary habits by adopting hypocaloric diets and eating more meals per day, as per nutritional counseling [24].

The results of the present study showed that overweight and obese adolescent girls with PCOS are heavily influenced by their friends and peers in choosing fast food and snacks. Also, Kilanowski in a study in adolescents showed that friends encourage unhealthy food choices [25]. In this regard, Bruening et al. concluded in their study, dietitians and health professional may consider developing strategies to engage friends to promote adolescents' healthy dietary behaviors [26]. Also, in the present study, taste, color, shape and ease of access to fast foods, low price of junk foods (such as chips and cheese puffs), as well as mass media advertisement are among the reasons for leaning towards such kinds of food. Fitzgerald et al. concluded in their study, to develop effective nutrition interventions, it is important to gather child and adolescent input regarding factors perceived as influencing their food choices [27]. Several studies have shown that among adolescents, taste, color and shape are important factors in the process of food selection $[28,29]$. Due to complexity of nutritional behavior [30], modifying food habits of overweight and obese adolescent girls with PCOS is a comprehensive approach, in which all the mentioned points should be considered. Also, future research includes development of interventions to assist these adolescent girls with healthy-eating decision making.

Through presenting an image of food habits in overweight and obese adolescent girls with PCOS, for the first time, the present study is able to help for designing the necessary interventions to change the food habits and prevention of disease complications in these girls.

Although the findings of the present qualitative study can provide a deep understanding of food habits in overweight and obese adolescent girls with PCOS, the results may not be shared by normal weight adolescent girls with PCOS.

\section{Conclusion}

Overweight and obese adolescent girls with PCOS have inappropriate food habits, which can lead to complications such as infertility. Hence the necessities of designing and performing the required interventions to change the food habits, control the symptoms and complications of PCOS, and finally, improve the reproductive health of these girls.

\section{Abbreviations}

PCOS: Polycystic Ovary Syndrome; FGDs: Focus Group Discussions

\section{Acknowledgements}

We should thank the Vice-chancellor for Research of Isfahan University of Medical Sciences and Shiraz University of Medical Sciences for their support.

\section{Authors' contributions}

All the authors contributed to the conception and design of the study. $\mathrm{LH}$ drafted the first version of the manuscript. MN, FM and ME revised the manuscript. MN critically reviewed the manuscript for important intellectual content. All authors approved the final version.

\section{Funding}

Financial support by Isfahan University of Medical Sciences and Shiraz University of Medical Sciences, Research proposal No: 395885.

\section{Availability of data and materials}

The datasets generated and/or analyzed during the current research are not publicly available as individual privacy could be compromised but are available from the corresponding author on reasonable request.

Ethics approval and consent to participate

The Ethics Committee of the Isfahan University of Medical Sciences in Isfahan, Iran approved the protocol of this study (code number: IR.MUI.Rec. 
1395.3.885). Written informed consent is taken from each participant and for the participants under the age of 18; written informed consent is taken from a parent or legal guardian. Also, all participants in the focused groups provided written informed consent prior to taking part.

\section{Consent for publication}

Not applicable.

\section{Competing interests}

The authors declare that they have no competing interests.

\section{Author details}

${ }^{1}$ Student Research Committee, School of Nursing and Midwifery, Isfahan University of Medical Sciences, Isfahan, Iran. ${ }^{2}$ Department of Nursing and Midwifery, Kazerun Medical Sciences Branch, Islamic Azad University, Kazerun, Iran. ${ }^{3}$ Department of Midwifery and Reproductive Health, School of Nursing and Midwifery, Isfahan University of Medical Sciences, Isfahan, Iran. ${ }^{4}$ Department of Health Education and Promotion, School of Health, Isfahan University of Medical Sciences, Isfahan, Iran. ${ }^{5}$ Nutrition Research Center, Department of Clinical Nutrition, School of Nutrition and Food Sciences, Shiraz University of Medical Sciences, Shiraz, Iran.

\section{Received: 15 February 2020 Accepted: 27 May 2020}

\section{Published online: 04 June 2020}

References

1. Karli P, Ayan D. Evaluation of hormonal profile in polycystic ovary syndrome. IJISMS. 2018;2(5):5-8.

2. Al Khalifah RA, Flórez ID, Dennis B, Neupane B, Thabane L, Bassilious E. The effectiveness and safety of treatments used for polycystic ovarian syndrome management in adolescents: a systematic review and network metaanalysis protocol. Syst Rev. 2015:4(1):125.

3. Rehme MFB, Pontes AG, Goldberg TBL, Corrente JE, Pontes A. Clinical manifestations, biochemical, ultrasonographic and metabolic of polycystic ovary syndrome in adolescents. Rev Bras Ginecol Obstet. 2013;35(6):249-54.

4. Skiba MA, Islam RM, Bell RJ, Davis SR. Understanding variation in prevalence estimates of polycystic ovary syndrome: a systematic review and metaanalysis. Hum Reprod Update. 2018;24(6):694-709.

5. Abd Elmenim SO, Mohamed Emam AM. Effect of lifestyle changes on symptoms of polycystic ovarian syndrome in obese girls. IOSR JNHS. 2016; 5(3):1-10

6. Todd AS, Street SJ, Ziviani J, Byrne NM, Hills AP. Overweight and obese adolescent girls: the importance of promoting sensible eating and activity behaviors from the start of the adolescent period. IJERPH. 2015;12(2):2306-29.

7. Tee JYH, Gan WY, Tan K-A, Chin YS. Obesity and unhealthy lifestyle associated with poor executive function among Malaysian adolescents. PLoS One. 2018;13(4):e0195934.

8. Ogden CL, Carroll MD, Lawman HG, Fryar CD, Kruszon-Moran D, Kit BK, et al. Trends in obesity prevalence among children and adolescents in the United States, 1988-1994 through 2013-2014. JAMA. 2016;315(21):2292-9.

9. Elizondo-Montemayor L, Hernández-Escobar C, Lara-Torre E, Nieblas B, Gomez-Carmona M. Gynecologic and obstetric consequences of obesity in adolescent girls. J Pediatr Adolesc Gynecol. 2017;30(2):156-68.

10. Bhutta ZA, Makrides M, Prentice AM. Health and nutrition in adolescents and young women: preparing for the next generation. Nestlé Nutrition Institute Workshop Series: Switzerland; 2013

11. Eleftheriadou M, Stefanidis K, Lykeridou K, Iliadis I, Michala L. Dietary habits in adolescent girls with polycystic ovarian syndrome. Gynecol Endocrinol. 2015;31(4):269-71.

12. Domecq JP, Prutsky G, Mullan RJ, Hazem A, Sundaresh V, Elamin MB, et al. Lifestyle modification programs in polycystic ovary syndrome: systematic review and meta-analysis. J Clin Endocr Metab. 2013;98(12):4655-63.

13. Thomson RL, Buckley JD, Noakes M, Clifton PM, Norman RJ, Brinkworth GD. The effect of a hypocaloric diet with and without exercise training on body composition, cardiometabolic risk profile, and reproductive function in overweight and obese women with polycystic ovary syndrome. Obstet Gynecol Surv. 2009:64(4):244-5.

14. Kite C, Lahart IM, Afzal I, Broom DR, Randeva H, Kyrou I, et al. Exercise, or exercise and diet for the management of polycystic ovary syndrome: a systematic review and meta-analysis. Syst Rev. 2019;8:51.
15. Vilmann LS, Thisted E, Baker JL, Holm JC. Development of obesity and polycystic ovary syndrome in adolescents. Horm Res Paediatr. 2012;78(5-6): 269-78.

16. Creswell JW. Qualitative inquiry and research design: choosing among five approaches. California: Sage publications; 2012

17. Fritz MA, Speroff L. Clinical gynecologic, endocrinology and infertility. 8th ed. Philadelphia: Lippincott Williams and Wilkins; 2011.

18. Lin AW, Lujan ME. Comparison of dietary intake and physical activity between women with and without polycystic ovary syndrome: a review. Adv Nutr. 2014;5(5):486-96

19. Zhang J, Liu Y, Liu X, Xu L, Zhou L, Tan L, et al. High intake of energy and fat in Southwest Chinese women with PCOS: A population-based casecontrol study. PLoS One. 2015:10(5):e0127094

20. Hmedeh C, Ghazeeri G, Tewfik I. Nutritional management in polycystic ovary syndrome: challenges and opportunities. Int J Food Saf Nutr Pub Health. 2018;3(2):870-82.

21. Amirjani S, Asemi Z, Bazarganipour F, Aramesh S, Allan H, Sayadi M, et al. Dietary intake and lifestyle behaviour in different phenotypes of polycystic ovarian syndrome: a case-control study. J Hum Nutr Diet. 2019;32(4):413-21.

22. Eleftheriadou M, MRCOG LM, Stefanidis K, Iliadis I, Lykeridou A, Antsaklis A. Exercise and sedentary habits among adolescents with PCOS. J Pediatr Adolesc Gynecol. 2012;25:172-4.

23. Vatopoulou A, Tziomalos K. Management of obesity in adolescents with polycystic ovary syndrome. Expert Opin Pharmacother. 2020;21(2):207-11.

24. Carolo AL, Mendes MC, de Sá Rosa AC, Vieira CS, de Sá MF, Ferriani RA, dos Reis RM, et al. Nutritional counseling promotes changes in the dietary habits of overweight and obese adolescents with polycystic ovary syndrome. Rev Bras Ginecol Obstet. 2017;39(1):692-6.

25. Kilanowski JF. Influences on health decision making in Latino adolescent children of migrant and seasonal agricultural workers. J Pediatr Health Care. 2016:30(3):224-30

26. Bruening M, Eisenberg M, MacLehose R, Nanney MS, Story M, NeumarkSztainer D. The relationship between adolescents' and their friends' eating behaviors - breakfast, fruit, vegetable, whole grain, and dairy intake. J Acad Nutr Diet. 2012;112(10):1608-13.

27. Fitzgerald A, Heary C, Nixon E, Kelly C. Factors influencing the food choices of Irish children and adolescents: a qualitative investigation. Health Promot Int. 2010;25(3):289-98.

28. Askari Majabadi H, Solhi M, Montazeri A, Shojaeizadeh D, Nejat S, Khalajabadi Farahani F, et al. Factors influencing fast-food consumption among adolescents in Tehran: A qualitative study. Iran Red Crescent Med J. 2016:18(3):e23890.

29. Dowd AJ, Chen MY, Schmader T, Jung ME, Zumbo BD, Beauchamp MR. Psychosocial predictors of changes in adolescent girls' physical activity and dietary behaviors over the course of the go girls! Group-based mentoring program. Health Educ Res. 2016:31(4):478-91.

30. Hummel E, Hoffmann I. Complexity of nutritional behavior: capturing and depicting its interrelated factors in a cause-effect model. Ecol Food Nutr. 2016;55(3):241-57.

\section{Publisher's Note}

Springer Nature remains neutral with regard to jurisdictional claims in published maps and institutional affiliations.

Ready to submit your research? Choose BMC and benefit from:

- fast, convenient online submission

- thorough peer review by experienced researchers in your field

- rapid publication on acceptance

- support for research data, including large and complex data types

- gold Open Access which fosters wider collaboration and increased citations

- maximum visibility for your research: over $100 \mathrm{M}$ website views per year

At BMC, research is always in progress.

Learn more biomedcentral.com/submission 